\title{
Application of gentamicin-collagen sponge shortened wound healing time after minor amputations in diabetic patients - a prospective, randomised trial
}

\author{
Martin Varga ${ }^{1}$, Bedrich Sixta ${ }^{1}$, Robert Bem², Ivan Matia ${ }^{3}$, Alexandra Jirkovska ${ }^{2}$, Milos Adamec ${ }^{1}$
}

\author{
${ }^{1}$ Transplant Surgery Department, Institute for Clinical and Experimental Medicine, \\ Prague, Czech Republic \\ ${ }^{2}$ Department of Diabetes, Diabetes Centre, Institute for Clinical and Experimental \\ Medicine, Prague, Czech Republic \\ ${ }^{3}$ Department of Visceral, Transplantation, Thoracic and Vascular Surgery, \\ University of Leipzig, Leipzig, Germany
}

Submitted: 20 July 2011

Accepted: 2 January 2012

Arch Med Sci 2014; 10, 2: 283-287

DOI: 10.5114 /aoms.2014.42580

Copyright @ 2014 Termedia \& Banach

\section{Abstract}

Introduction: Diabetic foot infections are frequently polymicrobial.The lower tissue concentration of systemically administered antibiotics in diabetic patients was reported. Collatamp®EG (Syntacoll GmbH Saal/Donau, Germany) is a bioabsorbable, gentamicin impregnated collagen spongeused for local treatment. The aim of this randomized trial was to assess influence of gentamicin-collagen sponge applied to a wound on surgical outcomes after minor amputations in diabetic patients.

Material and methods: Fifty diabetic patients indicated for minor amputation in 2009 at our surgery department were included in the study. Patients were pre-operatively randomised into two groups. Twenty-five patients in group A were treated with gentamicin impregnated collagen sponge applied into wound peri-operatively while 25 patients in group B had minor amputation without gentamicin sponge.

Results: There was no significant difference in the demographic data, procedures performed, diabetes duration and peripheral vascular disease severity between the groups. The median glycosylated haemoglobin was $6.0 \%$ (range: $4.6-9.5 \%$ ) in group $A$ and $6.2 \%$ (range: $4.0-8.4 \%$ ) in control group B (non-significant). Median $\mathrm{TCPO}_{2}$ level was 44 (range: 13-67) in group $\mathrm{A}$ and 48 (range: 11-69) in control group B (non-significant). The median of wound healing duration in group A was 3.0 weeks (range: 1.7-17.1 weeks) compared to 4.9 weeks (range: $2.6-20.0$ weeks) in control group B. This was with a statistically significant difference $(p<0.05)$.

Conclusions: Application of gentamicin impregnated collagen sponge shortened wound healing duration after minor amputations in diabetic patients by almost 2 weeks.

Key words: wound healing, diabetic foot, amputation, gentamicin.

\section{Introduction}

The risk of foot ulceration in a diabetic patient's lifetime may be as high as $25 \%$ and it is the most common cause of amputation [1-4]. Because of remaining weight bearing residuum with better ambulation and a lower mortality rate, minor limb amputation is considered preferable to

\author{
Corresponding author: \\ Martin Varga MD \\ Transplant Surgery \\ Department \\ Institute for Clinical \\ and Experimental Medicine \\ 1958/9 Videnska St \\ 14021 Prague \\ Czech Republic \\ Phone: +420 261364105 \\ Fax: +420 261362822 \\ E-mail: mavg@ikem.cz
}


below the knee amputation [5-8]. However, complicated wound healing and subsequent re-amputations after limb salvage procedures are frequent with a reported average failure rate of $30 \%$ [9-12]. Insufficient blood supply and wound infection are the leading causes of impaired wound healing after minor amputations. Diabetic foot infections are frequently polymicrobial and the increased bacterial loading leads to an overall reduction in healing rates [4, 13-15]. Antibiotic administration is therefore an important component of diabetic foot wound healing. To be effective, antibiotic treatment requires an adequate tissue concentration exceeding the minimum bactericidal concentration (MBC) for the pathogens [16]. But a lower tissue concentration of antibiotics in diabetic patients compared with controls has been reported $[17,18]$. This might be due to impaired blood supply of the soft tissues caused by diabetic microangiopathy and it can lead to tissue concentration of the antibiotic that does not reach MIC which fails to resolve infection and sustains development of resistant microbial strains $[16,19]$. The solution could be local application of antibiotics [20].

Collatamp ${ }^{\oplus}$ EG (Syntacoll GmbH Saal/Donau, Germany) is a bioabsorbable, gentamicin-impregnated collagen sponge used for topical antimicrobial therapy. The implant contains $2.0 \mathrm{mg} / \mathrm{cm}^{2}$ of gentamicin sulfate and $2.8 \mathrm{mg} / \mathrm{cm}^{2}$ of bovine collagen. Gentamicin sulfate is an bactericidal aminoglycoside antibiotic which is active against many strains of Gram-positive and Gram-negative pathogens with a therapeutic serum level of $4-8 \mu \mathrm{g} / \mathrm{ml}$ and a toxic level of $12 \mu \mathrm{g} / \mathrm{ml}$ [19]. It also has a prolonged post-antibiotic effect [21]. The implant collagen is similar to human collagen and is degraded by human collagenase and absorbed. Gentamicin is initially released by passive diffusion from the sponge and then actively by sponge collagen degradation. The local concentration levels (up to $9000 \mathrm{\mu g} / \mathrm{ml}$ ) exceed the MBC for various bacteria and last for at least $72 \mathrm{~h}$ while serum levels remain below the established toxicity threshold of 10-12 $\mu \mathrm{g} / \mathrm{ml}$ [22-24].

The aim of this randomised trial was to assess the influence of the gentamicin-collagen sponge applied to the wound on surgical outcomes after minor amputations in diabetic patients.

\section{Material and methods}

Fifty diabetic patients ( 38 male, 12 female, median age: 62.5, range: 33-89 years) scheduled for minor amputation in 2009 at the Transplantation Surgery Department, Institute for Clinical and Experimental Medicine, Prague, were included in the study. All patients were informed preoperatively about the procedure and signed an informed consent form for the procedure. After the procedure, all patients were treated and followed up regularly at our podiatric clinic until the wound was healed. Patients were pre-operatively randomised into two groups. Twenty-five patients in group A were treated with a gentamicin-collagen sponge applied to the wound peri-operatively while 25 patients in group $B$ had the minor amputation without a locally applied gentamicin sponge. Of the 50 patients, 3 were lost to follow-up and 2 were excluded from the study because of a serious peri-operative finding resulting in open wound healing. Forty-five patients were available for follow-up (22 patients in group $A$ with a gentamicin-collagen sponge and 23 in control group B without one). Demographic data and patient characteristics are presented in Table I. Indications for amputation were non-healing ulceration (more than 6 weeks) with signs of osteomyelitis (X-ray, bone detection by probe). All wounds were primarily sutured over a drain. Systemically antibiotics were administered in all patients according to the antibiogram. Wounds were considered healed after at least 1 month without signs of skin breakdown and infection. Patients with open wound healing were excluded from the study. Data of patients' demographics, laboratory values, clinical findings, wound healing time and re-amputation rate were collected and compared between the groups. The study was approved by the regional ethics committee.

\section{Operative technique}

General, spinal or regional anesthesia was given depending on the anesthesiologist. Amputations of the forefoot were performed by three experienced surgeons. No tourniquets were used in any case. In group $\mathrm{A}$, a gentamicin-collagen sponge was applied and left in the wound before closure. In group B no additional treatment was applied. All wounds were then primarily closed without tension over the drain. The patients were maintained for non-weight bearing for the first few days until wound healing was observed. Then the wound was protected in half shoes or walking orthoses.

\section{Statistical analysis}

We used the $\chi^{2}$ test to compare demographic data. T-test or Mann-Whitney test was used to compare the mean values of age and laboratory values. The wound healing tendency and re-amputation rate were compared between groups by Fisher's exact test. A $p$ value under 0.05 was considered statistically significant.

\section{Results}

There was no significant difference in the demographic data, procedures performed, laboratory val- 
Table I. Characteristics of the groups

\begin{tabular}{|c|c|c|c|}
\hline Parameter & $\begin{array}{c}\text { Group A } \\
\text { Gentamicin + }\end{array}$ & $\begin{array}{c}\text { Group B } \\
\text { Gentamicin - }\end{array}$ & Value of $p$ \\
\hline Number of patients & 22 & 23 & \\
\hline Women, $n(\%)$ & $4(18)$ & $8(35)$ & NS \\
\hline Age, median (min.-max.) [years] & $61(43-89)$ & $63(33-83)$ & NS \\
\hline RTG osteomyelitis, $n$ (\%) & $9(41)$ & $15(65)$ & NS \\
\hline Diabetes type one, $n(\%)$ & $4(18)$ & $3(13)$ & NS \\
\hline Diabetes duration, median (min.-max.) [years] & $19(5-47)$ & $23(2-54)$ & NS \\
\hline Vascular intervention, $n(\%)$ & $11(50)$ & $14(61)$ & NS \\
\hline Ischaemic heart disease, $n(\%)$ & $8(36)$ & $6(26)$ & NS \\
\hline Hypertension, $n$ (\%) & $13(59)$ & $15(65)$ & NS \\
\hline Renal insufficiency, $n$ (\%) & $5(23)$ & $7(30)$ & NS \\
\hline $\mathrm{TcPO}_{2}$, median (min.-max.) [mm Hg] & $44(13-67)$ & $48(11-69)$ & NS \\
\hline $\mathrm{HbA}_{1 \mathrm{c}}$, median (min.-max.) (\%) & $6.0(4.6-9.5)$ & $6.2(4.0-8.4)$ & NS \\
\hline Albumin, median (min.-max.) [g/l] & $33(24-42)$ & $34(22-42)$ & NS \\
\hline Creatinine, median (min.-max.) $[\mu \mathrm{mol} / \mathrm{l}]$ & $108(58-700)$ & $98(50-260)$ & NS \\
\hline White blood cell count, median (min.-max.) $\left(\times 10^{9} / 1\right)$ & $7.8(5.7-13.0)$ & $7.5(5.4-14.0)$ & NS \\
\hline C-reactive protein, median (min.-max.) [mg/l] & $5(1-130)$ & $10(2-120)$ & NS \\
\hline
\end{tabular}

$\mathrm{NS}-$ not significant difference, $\mathrm{TCPO}_{2}-$ transcutaneous oxygen tension, $\mathrm{HbA}_{1 c}-$ haemoglobin $\mathrm{A}_{1 \mathrm{c}}$ percentage

ues, X-ray signs of osteomyelitis, diabetes duration or peripheral vascular disease severity between the groups (Table I). In total, 7 patients with type one diabetes were enrolled in the study (4 in group $A$ and 3 in group $B$ ). But no significant influence on postoperative outcome was observed depending on type of diabetes. The median glycosalated haemoglobin $\left(\mathrm{HbA}_{1 \mathrm{c}}\right.$ ) level was 6.0\% (range: 4.6-9.5\%) in group $A$ and $6.2 \%$ (range: $4.0-8.4 \%$ ) in control group B (non-significant). Closer comparison of patients regarding the quality of diabetes compensation $\left(\mathrm{HbA}_{1 c}\right.$ level under or over $6.0 \%$ ) was without a significant influence on duration of wound healing or hospital stay. Nor did a lower level of albumin (under $30.0 \mathrm{~g} / \mathrm{l}$ ) as a sign of impaired metabolic status have a negative influence on wound healing and hospital stay. Median $\mathrm{TcPO}_{2}$ level before amputation was 44 (range: 13-67) in group A and 48 (range: 11-69) in control group $B$ (non-significant). These levels indicate good perfusion for satisfactory wound healing [25]. X-ray signs of osteomyelitis were present in 9 patients in the gentamicin group and 15 in the control group. Low levels of C-reactive protein (CRP) (median $9 \mathrm{mg} / \mathrm{l}$, range: 1-130 mg/l) and white blood cell count (median $7.6 \times 10^{9} /$ l, range: $5.4-14 \times 10^{9} /$ l) as signs of systemic infection indicate chronic ulceration without acute inflammation. The most common cultivation findings were Staphylococcus aureus, Enterococcus faecalis, Klebsiella spp. and Pseudomonas aeruginosa (Table II). Methicillin-resistant Staphylococcus aureus (MRSA) was present in 4 cases and negative cultivation was present also in 4 cases.
Cultivation findings were without a significant difference between the groups. We performed 30 single ray resections ( 14 in group $A, 16$ in group $B$ ), 11 multiple ray resections ( 5 in group $A, 6$ in group $B$ ) and 4 trans-metatarsal amputations ( 2 in each group).

Application of the gentamicin-impregnated collagen sponge shortened wound healing duration after minor amputations in diabetic patients by almost 2 weeks when compared to the control group. The median wound healing duration in gentamicin group A was 3.0 weeks (range: 1.7-17.1 weeks). In control group $B$, the median wound healing duration was 4.9 weeks (range: 2.6-20.0 weeks). This was a significant difference $(p<0.05)$.

The median hospital stay was 11 days in gentamicin group A (range: 9-36 days) and 15 days (range: 7-38 days) in control group B. Three reamputations were necessary for a non-healing wound in group A (1 major and 2 minor amputations). In group B, 4 minor re-amputations were performed. This was without a significant difference between the groups or between the different types of procedures.

\section{Discussion}

Our results show that application of the gentamicin sponge significantly shortened wound healing duration by almost 2 weeks when compared to the control group. But we did not observe any positive effects on the length of hospital stay, 
Table II. Microbiological findings in our groups

\begin{tabular}{|lccc|}
\hline Microbiological findings & $\begin{array}{c}\text { Group A } \\
\text { Gentamicin }\end{array}$ & $\begin{array}{c}\text { Group B } \\
\text { Gentamicin }-\end{array}$ & Value of $p$ \\
\hline Staphylococcus aureus & 14 & 11 & NS \\
\hline Enterococcus faecalis & 6 & 5 & NS \\
\hline Klebsiella species & 5 & 5 & NS \\
\hline Pseudomonas aeruginosa & 4 & 3 & NS \\
\hline Corynebacterium species & 4 & 3 & NS \\
\hline Escherichia coli & 2 & 3 & NS \\
\hline Proteus species & 1 & 1 & NS \\
\hline MRSA & 1 & 2 & NS \\
\hline Streptococcus species & 2 & 2 & NS \\
\hline Negative finding & 2 & 3 & \\
\hline
\end{tabular}

NS - not significant difference

number of revisions for wound breakdown or number of subsequent re-amputations. This is in accord with the retrospective study of Krause et al., who observed wound healing in less time in 49 limbs after trans-metatarsal amputation when bioabsorbable calcium sulphate antibiotic beads were used compared to a control group (16 limbs) [9]. They also reported a lower revision rate for wound breakdown in the antibiotic beads group $(p<0.05)$, but we did not confirm this in our study.

Insufficient blood supply, wound infection and patients' non-adherence to the treatment regime are the leading causes of impaired wound healing after minor amputations. Pre-operative data show that both study groups were in the same state of health with on average satisfactory diabetes control, limb blood supply and signs of infection. Performed amputation procedures were without a significant difference between the groups. All outpatients were treated and followed up at our podiatric clinic. Griffis et al. reported that antimicrobial therapy relies on adequate tissue concentration and delivery to the target site after systemic administration and relies on a functional circulatory system [19]. Topical administration using a biocompatible carrier affords accurate delivery while minimizing the risks of systemic complications. As Browne et al. observed, increased bacterial loading leads to a reduction in the wound healing rate [13]. Gentamicin as a bactericidal antibiotic released from the gentamicin-collagen sponge with local concentration levels exceeding the $M B C$ for various bacteria might decrease this bacterial loading with a positive influence on wound healing. Our study confirmed this suggestion when the local application of gentamicin led to a shorter wound healing time.

We did not observe any side effects after local application of the gentamicin-collagen sponge in our group. Aminoglycoside ototoxicity and nephrotoxicity after intravenous or peroral administration are serious complications leading to the cautious use of antibiotics. Nevertheless, local use of gentamicin in diabetic patients does not reach the appropriate systemic concentration for these complications $[19,24]$.

Systemic antibiotics were, according to the international consensus on the diabetic foot, administered to all patients according to the antibiogram until the wound was completely healed. Whether the local application of gentamicin, without systemic administration, is sufficient to ensure the same wound healing rate remains unsolved [25].

While this presented study is on a small group of patients, further investigation with more patients would be necessary to confirm our results. Another factor for consideration is that our study enrolled only patients with diabetic foot syndrome. If the influence of the gentamicin-impregnated collagen sponge in non-diabetic patients would be the same remains unsolved.

In conclusion, application of the gentamicin-impregnated collagen sponge shortened wound healing duration after minor amputations in diabetic patients by almost 2 weeks ( 3.0 weeks vs. 4.9 weeks). A completely healed wound leads to less frequent outpatient visits and lower consumption of antibiotics with a lower complication rate due to their systemic administration. This can also have a positive economic impact. Wound healing in less time also enables earlier rehabilitation and ambulation of the patients and can thereby improve their quality of life.

\section{References}

1. Singh N, Armstrong DG, Lipsky BA. Preventing foot ulcers in patients with diabetes. JAMA 2005; 293: 217-28. 
2. Pecoraro RE, Reiber GE, Burgess EM. Pathways to diabetic limb amputation. Basis for prevention. Diabetes Care 1990; 13: 513-21.

3. Larsson J, Agardh CD, Apelqvist J, Stenstrom A. Longterm prognosis after healed amputation in patients with diabetes. Clin Orthop Relat Res 1998; 350: 149-58

4. Consensus Development Conference on Diabetic Foot Wound Care: 7-8 April 1999, Boston, Massachusetts. American Diabetes Association. Diabetes Care 1999; 22: 1354-60.

5. Pinzur MS, Gold J, Schwartz D, Gross N. Energy demands for walking in dysvascular amputees as related to the level of amputation. Orthopedics 1992; 15: 1033-6.

6. Waters RL, Perry J, Antonelli D, Hislop H. Energy cost of walking of amputees: the influence of level of amputation. J Bone Joint Surg Am 1976; 58: 42-6.

7. Lee JS, Lu M, Lee VS, Russell D, Bahr C, Lee ET. Lower-extremity amputation. Incidence, risk factors, and mortality in the Oklahoma Indian Diabetes Study. Diabetes 1993; 42: 876-82.

8. Oliveira CS, Anjos DMC, Gomes LPO, Sampaio LMM, Correa JCE. Assessment of plantar pressure and balance in patients with diabetes. Arch Med Sci 2010; 6: 43-8.

9. Krause FG, deVries G, Meakin C, Kalla TP, Younger AS. Outcome of transmetatarsal amputations in diabetics using antibiotic beads. Foot Ankle Int 2009; 30: 486-93.

10. Mueller MJ, Allen BT, Sinacore DR. Incidence of skin breakdown and higher amputation after transmetatarsal amputation: implications for rehabilitation. Arch Phys Med Rehabil 1995; 76: 50-4.

11. Pollard J, Hamilton GA, Rush SM, Ford LA. Mortality and morbidity after transmetatarsal amputation: retrospective review of 101 cases. J Foot Ankle Surg 2006; 45: 91-7.

12. Sanders LJ, Dunlap G. Transmetatarsal amputation. A successful approach to limb salvage. J Am Podiatr Med Assoc 1992; 82: 129-35

13. Browne AC, Vearncombe M, Sibbald RG. High bacterial load in asymptomatic diabetic patients with neurotrophic ulcers retards wound healing after application of Dermagraft. Ostomy Wound Manage 2001; 47: 44-9.

14. Armstrong DG, Lipsky BA. Diabetic foot infections: stepwise medical and surgical management. Int Wound J 2004; 1: 123-32.

15. Caputo GM, Joshi N, Weitekamp MR. Foot infections in patients with diabetes. Am Fam Physician 1997; 56: 195-202.

16. Percival SL, Cutting KF. Biofilms: possible strategies for suppression in chronic wounds. Nurs Stand 2009; 23: 64, 66, 68 passim.

17. Skhirtladze K, Hutschala D, Fleck T, et al. Impaired target site penetration of vancomycin in diabetic patients following cardiac surgery. Antimicrob Agents Chemother 2006; 50: 1372-5.

18. Sedivy J, Petkov V, Jirkovska A, et al. Optimization of amoxicillin/clavulanate therapy based on pharmacokinetic/pharmacodynamic parameters in patients with diabetic foot infection. Klin Mikrobiol Infekc Lek 2004; 10: $167-75$

19. Griffis CD, Metcalfe S, Bowling FL, Boulton AJ, Armstrong DG. The use of gentamycin-impregnated foam in the management of diabetic foot infections: a promising delivery system? Expert Opin Drug Deliv 2009; 6: 639-42.

20. Melichercik P, Jahoda D, Bartak V, Klapkova E, Nyc O, Pokorny D. In vitro assessment of vancomycin released from bone grafts. Acta Chir Orthop Traumatol Cech 2010; 77: 411-5.
21. Craig WA. Post-antibiotic effects in experimental infection models: relationship to in-vitro phenomena and to treatment of infections in man. J Antimicrob Chemother 1993; 31 Suppl D: 149-58.

22. Radu FA, Bause M, Knabner P, Lee GW, Friess WC. Modeling of drug release from collagen matrices. J Pharm Sci 2002; 91: 964-72.

23. Ruszczak Z, Friess W. Collagen as a carrier for on-site delivery of antibacterial drugs. Adv Drug Deliv Rev 2003; 55: 1679-98.

24. Stemberger A, Grimm H, Bader F, Rahn HD, Ascherl R. Local treatment of bone and soft tissue infections with the collagen-gentamicin sponge. Eur J Surg Suppl 1997; 578: 17-26.

25. Kalani M, Brismar K, Fagrell B, Ostergren J, Jorneskog G. Transcutaneous oxygen tension and toe blood pressure as predictors for outcome of diabetic foot ulcers. Diabetes Care 1999; 22: 147-51. 